\title{
Design of a high-altitude long-endurance solar-powered unmanned air vehicle for multi-payload and operations
}

\author{
G Romeo*, G Frulla, and E Cestino \\ Department of Aerospace Engineering, Turin Polytechnic University, Corso Duca Abruzzi, Turin, Italy
}

The manuscript was received on 1 June 2006 and was accepted after revision for publication on 22 September 2006.

DOI: 10.1243/09544100JAERO119

\begin{abstract}
Several researches are being carried out at the Politecnico di Torino with the aim of designing a high altitude very-long endurance/unmanned air vehicle (HAVE/UAV). Being able to fly in the stratosphere $(15-20 \mathrm{~km})$ and with an endurance of about 4 months offers an advantage and possibility that is presently not available with conventional aircraft or satellites. A computer program has been developed to design the platform. The change in solar radiation over a period of a year, the altitude, masses, and efficiencies of the solar and fuel cells, as well as the aerodynamic, structural, flight mechanics, and aeroelastic performances have all been taken into account. Extensive use has been made of high modulus graphite/epoxy when designing the structure in order to minimize the airframe weight, but also to guarantee the required stiffness and aeroelastic performance.

A blended wing body (BWB) configuration has been selected for solar HAVE aircraft multi payload and operation (SHAMPO) with eight brushless electric motors, as the result of a preliminary design. The BWB solution has been designed according to the conventional procedures and airworthiness regulations. It seems to be the best compromise between performance, available surfaces for solar cells and volume for multi-payload purposes, compared to conventional design.

Several profiles and wing plans have been analysed and optimized to achieve the best efficiency using the Xfoil and Vsaero computational fluid dynamics (CFD) software. A finiteelement method and a classical theoretical analysis was carried out using the Msc/Patran/ Nastran code to predict the static and aeroelastic behaviour of the SHAMPO. Aeroelastic analysis has been performed starting with a classical linear flutter analysis and considering an undeformed equilibrium condition. Classical linear flutter speed show as the airworthiness requirements has been achieved in the case of SHAMPO configuration. A preliminary non-linear aeroelastic model is introduced in the design process in order to deal with specific phenomena correlated with high static structural deflections occurring during standard flight conditions. Important flutter speed reduction (i.e. up to 42 per cent in special cases) are possible including such kind of phenomena.
\end{abstract}

Keywords: aircraft design, high altitude very-long endurance, unmanned air vehicle, aerodynamic, stability, structure, aeroelastic, flexible wing

\section{INTRODUCTION}

Stratospheric platforms, geostationary located at altitudes of $17-25 \mathrm{~km}$, offer the possibility of

\footnotetext{
*Correspondence author: Department of Aerospace Engineering, Turin Polytechnic University, Corso Duca Abruzzi 24, Turin, 10129, Italy.email: giulio.romeo@polito.it
}

becoming a new generation of infrastructural elements for future Earth observation and telecommunication systems. They can act as pseudosatellites, but with the advantage of being much cheaper and closer to the ground and they can perform missions that offer greater flexibility. They could be self-launched, easily recovered for maintenance, whenever necessary, and moved to cover different regions, if desired. They allow a more 
detailed land vision, due to their relative closeness to the Earth, at a much lower cost than conventional satellites; furthermore they are geostationary located and do not suffer from typical satellite revisiting time limits from $12 \mathrm{~h}$ up to 20 days. These platforms could cover a wide range of applications: real-time monitoring of seismic-risks or volcanic areas, early forest fire detection, border security surveillance, pipeline, and power-line surveys; telecommunication services such as cellular-telephone networks, photogrammetry, hydrographic monitoring system, agriculture monitoring, etc.

Unmanned an vehicle (UAVs) have been used for over 40 years by the military services for dangerous missions and surveillance. The technology has been relatively expensive and unreliable, as cost and safety issues were considered of secondary importance to performance. However, technology has advanced sufficiently for this highly technical area of the aeronautical industry to be developed into a new growing UAV civilian industry. The United States has already begun investing in this field and has initiated a massive drive to develop this new industry. Europe also has the necessary technologies and should now also support and encourage industry to take advantage of new technological approaches in order to successfully become a leading participant in this field.

In a recent business market study carried out by Frost and Sullivan [1], the global market for UAVs in civil and commercial applications will be close to US $\$ 2$ billion by 2014 . The largest market shares are expected to pertain to Coastguard and Maritime Surveillance operations, Border Security, and Forest Fire Management.

From a flying altitude of $18 \mathrm{~km}$, an area of about $300-400 \mathrm{~km}$ in diameter would be covered for communication transmission if the onboard antenna irradiation diagram is properly chosen. This would mean that about seven to eight platforms could cover the entire south Mediterranean Sea, from Spain to Turkey (Fig. 1), creating an electronic illegal immigration barrier as well as a secure border control system.

Compared to the present cost of airborne systems (5000-7000 €/flight hour), high altitutde long endurance/unmanned air vehicles (HALE/UAVs) offer clear advantages in monitoring missions, as continuous observations will be performed throughout the year over the area of interest and all the required data will usually be available immediately. The main advantage of the very-long endurance solar-powered autonomous aircraft (VESPAA) is that this system has less climbing and descending events, which is important when considering interference with aviation traffic. Other HALE-UAV configurations have a very limited endurance (24-36 h), which would drastically increase any

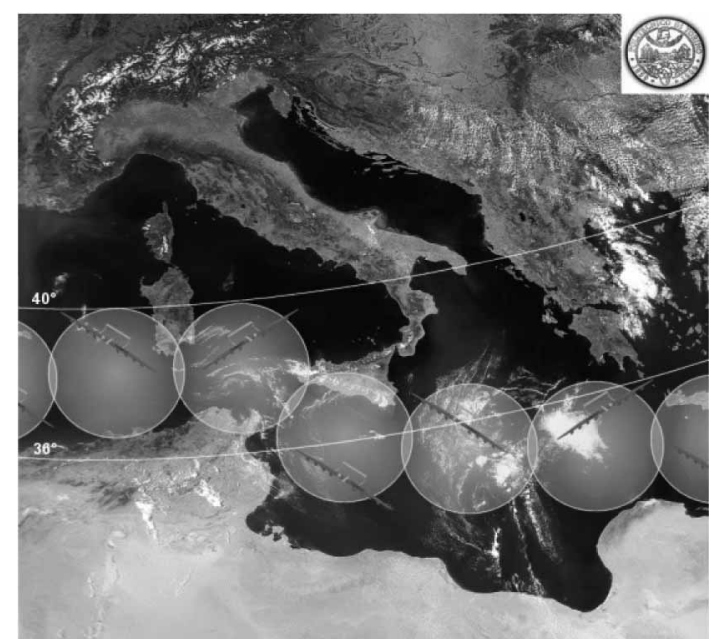

Fig. 1 HeliPlat ${ }^{\circledR}$ Border Surveillance over the Mediterranean Sea

potential collision risk with civil aviation traffic. Double the number of UAVs would be necessary to continuously guarantee the surveillance service, thus the system total life cycle cost would be increased to a great extent. Other medium altitude long endurance (MALE)-UAVs have, as a further disadvantage, the fact that a much higher number of UAVs are necessary to continuously cover the entire Mediterranean Sea, since the covered area decreases with the square value of the flying altitude (Fig. 2); the total life cycle cost system would increase remarkably with a MALE configuration. Very high endurance, in fact, calls for high mission reliability requirements of the air vehicle, its systems and payload.

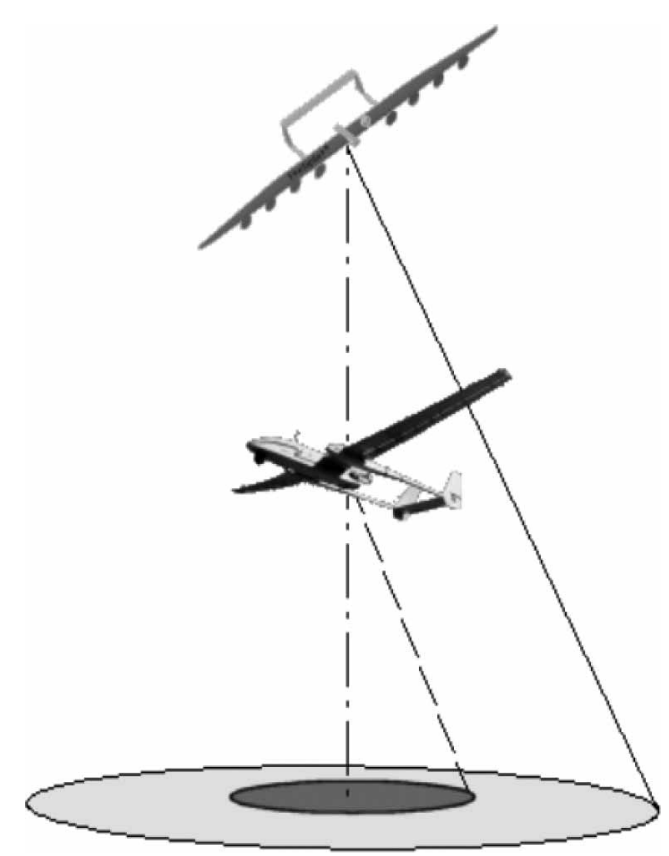

Fig. 2 HAVE / MALE monitoring area comparison 
An endurance of several months would only be possible using a solar- and hydrogen-powered platform. The vehicle would climb to $17-20 \mathrm{~km}$ mainly taking advantage of direct sun radiation. Any electric energy not required for the propulsion and payload operations would be pumped back into the electrolyzer system that would convert the water into hydrogen and oxygen fuel; during the night, the platform would maintain altitude, thanks to the fuel cell system, which would produce electricity and water as a by-product of the reaction; the geostationary position would be maintained by a level turning flight.

Several types of high altitude stratospheric platforms have already been designed $[\mathbf{2}-\mathbf{5}]$. At the end of 1994, NASA started the Environmental Research Aircraft and Sensor Technology (ERAST) program; one of the four drones is the Pathfinder solar platform, which exceeded $24 \mathrm{~km}$ of altitude during a $15 \mathrm{~h}$ flight. In the summer of 2001, the Helios solarpowered platform set a new world record of $29.3 \mathrm{~km}$. Although a flight of several days was planned for summer 2003, the program suffered a devastating setback when the Helios prototype was lost in June 2003 in a flight mishap during a shakedown mission. The Helios wing bent dramatically and oscillated, and then the wing spar broke. It seems very likely that Helios crashed because of undamped pitch oscillations that led to a partial structural failure of the very flexible Kevlar/carbon spar. In the interim status report, the investigation board stated that the "undamped pitch oscillations may be related to the complex interactions between the aerodynamic, structural, stability and control, and propulsion systems on a flexible aircraft.'

The main innovative aspects of the VESPAA are the following.

1. The design of the first European aerodynamic solar-powered platform that would be able to remain continuous in flight for very long periods of time (4 months).

2. Low noise and zero emission aircraft. The advantage of zero emissions is particularly important for environmental monitoring.

3. The first European solar-powered platform to validate the feasibility and reliability of solar cells, fuel cells and brushless electric motors.

All these features lead to:

(a) reduced cost per flight hour (thanks to a large increase in the endurance flight hours);

(b) potentially increased acquisition cost, while reducing the cost of maintenance and spare parts;

(c) reduced cost - larger area coverage per platform, thus, fewer platforms per area are required; (d) improved operational safety - due to the fact that the flight would occur above aviation traffic, resulting in limited interference with it, and above adverse weather;

(e) lower propagation delay compared to satellites.

The Department of Aerospace Engineering at the Politecnico di Torino (POLITO/DIASP, Scientific Responsible Prof. Romeo) has acquired a great deal of experience, starting from 1994, in the design of solar-powered UAV as high altitude very long endurance platform positioned in the stratosphere at an altitude of $17-20 \mathrm{~km}$ and with an endurance of about four months [6-14]. Started under a grant from the Italian Space Agency (ASI), a great amount of work was carried out within two European funded projects (HeliPlat ${ }^{\circledR}$ and Capecon) whose final task was to fill the European gap in knowledge and feasibility of such kinds of innovative systems.

The ESA-STRATOS definition study was also performed for stratospheric platforms, driven by the possibility of replacing or complementing space systems with stratospheric platforms, particularly in the area of telecommunication applications. The main objective of this study was to explore the possibility of the development and operation of a European stratospheric platform based on a sound analysis of possible service areas, assessment of available and future technologies, and to perform a conceptual design for the most suitable platform concept that would answer the requirements of future telecommunication markets (Fig. 3).

Two reference configurations for stratospheric platforms were selected from a number of studies on stratospheric platforms and some existing designs of stratospheric aircraft: an aerodynamic one and an aerostatic one. Both are electrically driven solarpowered designs. Detailed investigations into the aerodynamic and aerostatic reference design led to the identification of the critical platform technologies. Most of these technologies are common to both platform categories. On the basis of the necessary technology development, a stepwise approach was sustained using both types of platforms in the prototype and test phase. This approach indicates that an operable stratospheric platform could be developed within 10 years.

There is no clear rule on whether aerostatic or aerodynamic systems are in general the preferable solution for stratospheric platforms. Because of their different characteristics and behaviour, the platform selection very much depends on the applications and the corresponding flight envelope.

A comparison of the technical reference designs with the payload requirements from the system architecture showed that the smaller aerodynamic configuration (payload of $150 \mathrm{~kg}$ and available 

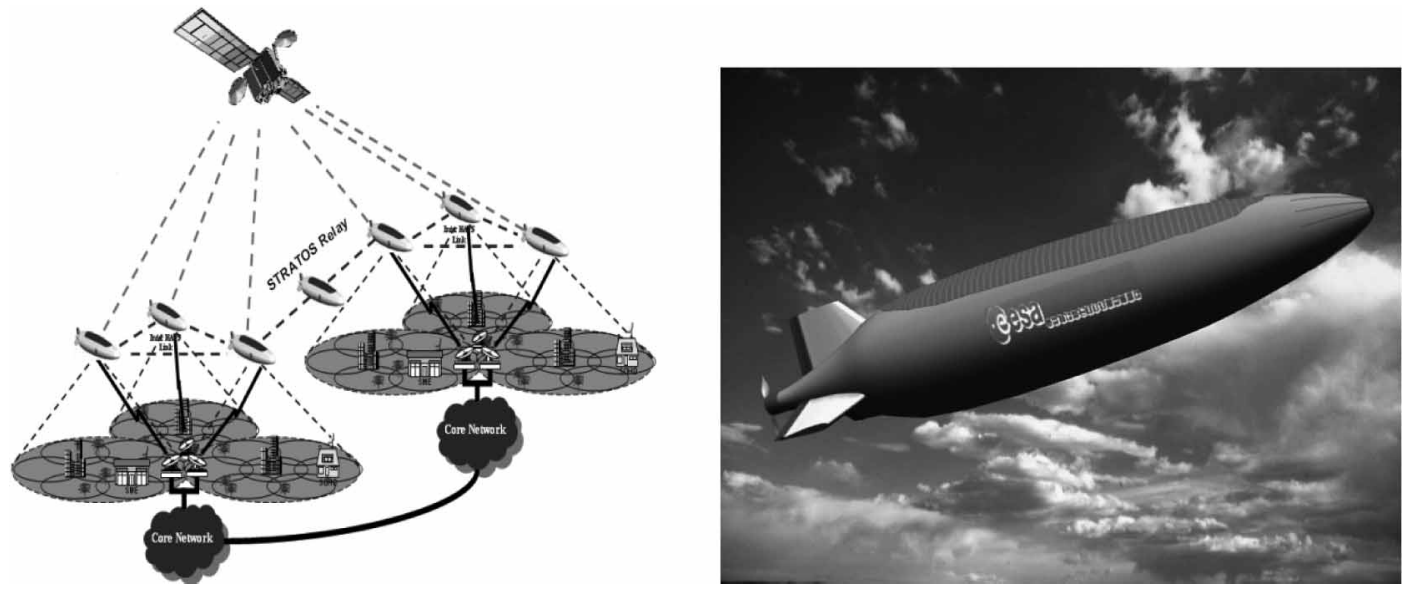

Fig. 3 Aerostatic HAVE-UAV for telecom applications

power for payload of $1.5 \mathrm{~kW}$ ) would be suitable as a preliminary demonstrator of all the key technologies and could also demonstrate some of the service capabilities, mainly for Earth observation, while the larger aerostatic design (payload greater than $1000 \mathrm{~kg}$ and power of $20 \mathrm{~kW}$ ) would be required for an operational telecom service scenario).

On the other hand, for a rigorous station-keeping position throughout the year, a jet stream of up to $40 \mathrm{~m} / \mathrm{s}$ in the wintertime could be difficult to be contrasted because of the wind sensitivity of aerostatic platforms. However, because the aerostatic law imposes UAV dimensions, a higher power energy would be possible as the efficiency of the fuel cells and solar cells would increase. The high cost of each airship, in comparison to the aerodynamic platform, is another critical point.

Solar-powered stratospheric platforms are also preferable to other HALE/MALE platforms because of:

(a) environment-friendly operations (no emission in the lower stratosphere where the highly sensitive ozone layer is located);

(b) similarity of the technologies to space-based systems (power systems, autonomous operations, and payloads);

(c) similarity in operations to space based systems (launching, very-long operations, etc.).

Regenerative power technologies, such as thin film photovoltaic (PV) arrays, fuel cells, electrolyzers, power, and management systems, are the keys to achieve long-endurance regenerative UAV. Since the basic power source, the sun, is not available throughout the whole day, effective designs for managing, collecting, storing, and consuming energy are needed to make the platform a real alternative to satellites for night and day missions.

The design of a vehicle that is able to operate solely from the incoming energy of the sun is a fine balance between energy collection and energy consumption. This energy balance is influenced by a number of factors such as the operational environment and the capabilities and efficiencies of the power system components. Considering the solar radiation that is available at $17 \mathrm{~km}$ of altitude for a panel surface placed parallel to the Earth's surface, a maximum specific solar power of 675 and $475 \mathrm{~W} / \mathrm{m}^{2}$, respectively, at $36^{\circ}$ and $45^{\circ} \mathrm{N}$ would be detectible on the worst day (December 21). During the best optimal day, the maximum specific solar power is about 1240 and $1190 \mathrm{~W} / \mathrm{m}^{2}$, respectively, at $36^{\circ}$ and $45^{\circ} \mathrm{N}$. The energy balance for a HeliPlat configuration flying in June at $17 \mathrm{~km}$ of altitude is reported in Fig. 4. A very large amount of electric power would be available from sun radiation, with a peak at $180 \mathrm{~kW}$. However, because of the low solar cell efficiency taken into consideration (21 per cent), just a small amount of power would be available for the platform. With an optimised design of the

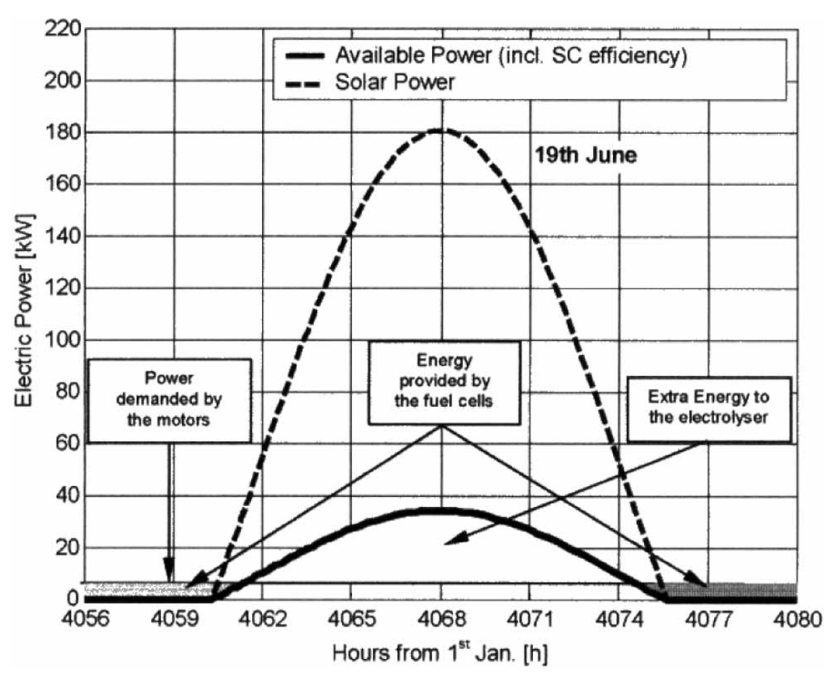

Fig. 4 Solar power distribution and energy balance 
platform, just a small amount of power would be required by the motors to fly (about $6.5 \mathrm{~kW}$ ); the extra energy available from the solar cells would be supplied to the electrolyser for the production of hydrogen and oxygen for the night flight.

To accurately determine the feasibility of the high altitude aircraft concept, a detailed model of the wind environment is also necessary. This wind model would provide mean and 99th percentile winds along the area of interest for the analysis.

Although the wind does not affect the aircraft's power generation, it has a significant effect on its drag and power consumption. A wind study was therefore performed at several locations. The upper air data climatic tables recorded by the Italian Air Force from 1963 to 1997 were analysed to obtain the wind profiles as a function of the altitude (from $1000 \mathrm{hPa}(111 \mathrm{~m})$ to $10 \mathrm{hPa}(31055 \mathrm{~m}))$ for several latitudes. Analysing the data (Fig. 5(a)), it was clear that the jet-streams are at a minimum between the altitudes of 18 and $22 \mathrm{~km}$, depending on the time of year. An average wind speed of $17.1 \mathrm{~m} / \mathrm{s}$ was recorded in January at $18 \mathrm{~km}$ in altitude. The recording frequency of such high jet streams, from 1963 to 1997, was also investigated (Fig. 5(b)). In January, 60 per cent of the events recorded were in a lower speed range than $15 \mathrm{~m} / \mathrm{s}$; a higher speed than $35 \mathrm{~m} / \mathrm{s}$ was recorded just 56 times, in more than 2000 events, over 34 years, although in only a few cases (twice in 34 years), high wind speeds of up to $60 \mathrm{~m} / \mathrm{s}$ were recorded.

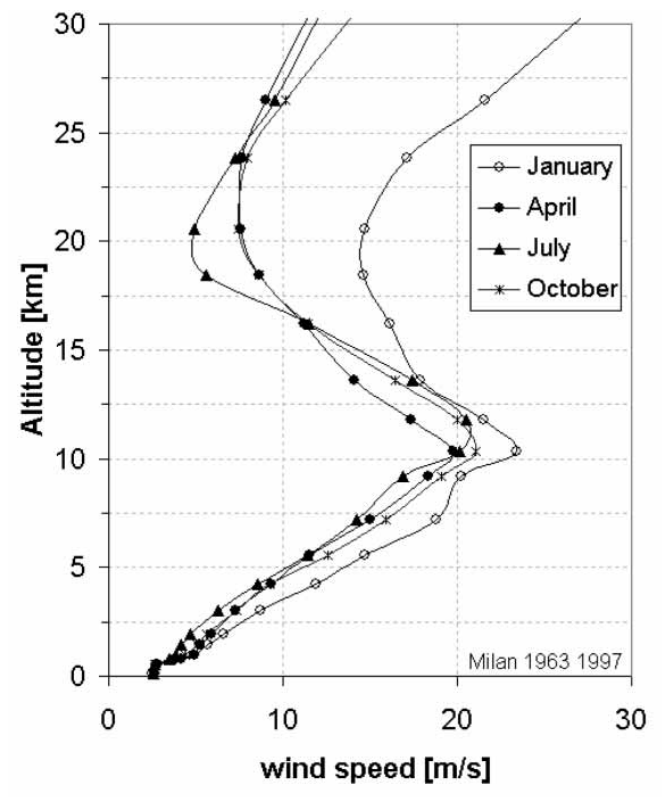

(a)
From the educational point of view, design of a solar-powered airplane presents an interesting case to introduce students to the procedures and practices of aircraft design as a means of illustrating the often conflicting requirements of the many involved disciplines. In such kind of advanced aircrafts the difficulties with sun-powered flight make an accurate integration of the structural weight optimisation, aerodynamics, propulsion efficiency, and electronic devices much more critical. In addition students approach the work with present time problems such as non-linear aeroelasticity or design of advanced composite structures.

\section{CAPECON PROJECT}

Seven potential configurations have been evaluated as part of the EC funded Project 'CAPECON: Civil UAV Applications and Economic Effectivity of Potential Configuration Solutions': three HALE (with the Politecnico di Torino - Department of Aerospace Engineering Scientific Responsible: Prof. ROMEO as work package leader of solar, modular and blended configuration design, and Task leader for solar configuration design), two MALE and two Rotary UAV concepts. In addition, a comprehensive cost model has been developed for the first time to assess the economic advantages and disadvantages of the various configurations. On the basis of these evaluations, some recommendations were made for

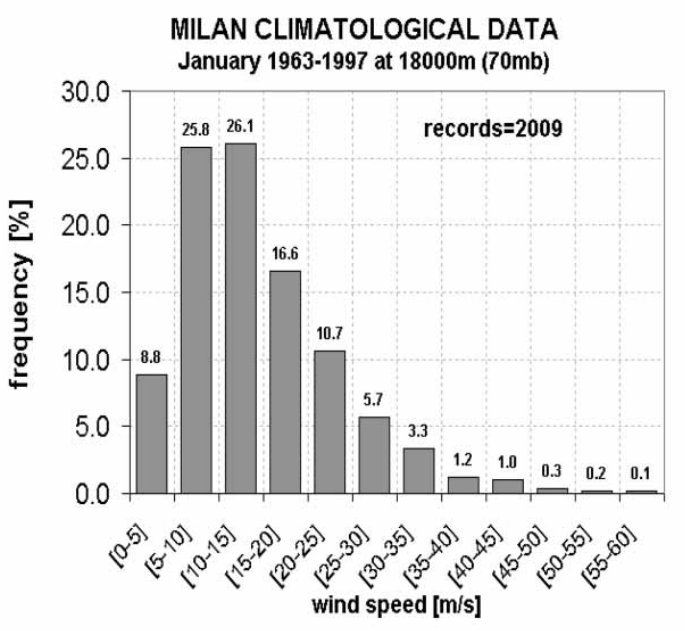

(b)

Fig. 5 (a) Average wind speed profile for several altitudes and seasons. (b) Statistic distribution at $18 \mathrm{~km}$ in January 
further critical technology (CT) and technology program (TP) activities within the sixth framework.

The basic requirements for the CAPECON Solar HALE UAV configuration have been first established. The initial starting point requirements for the Solar HALE UAV configuration have been obtained from previous HeliPlat experience know-how. In particular, the platform would accommodate a maximum user payload mass of $130-150 \mathrm{~kg}$ and consume a maximum electrical power of 1.3-1.5 KW. A maximum total mass of $850-900 \mathrm{~kg}$ is expected for 6 -month flight at an altitude of $17 \mathrm{~km}$. The choice of $17 \mathrm{~km}$ is a compromise between less wind and low air density - that means very low Reynolds numbers and solar radiation.

The following tasks have been carried out by POLITO/DIASP during the HALE UAV solar configuration design.

1. Ground rules and assumptions: the solar-powered HALE UAV has been designed, considering the Mediterranean Sea border patrol and forest fire monitoring during summer time as possible applications. The platform would fly for 6 months, starting on the first of April, at an altitude of $17 \mathrm{~km}$ for a latitude below $44^{\circ} \mathrm{N}$.

2. Preliminary design: including sizing, geometrical definition (three views and three-dimensional), external layout, aerodynamic definition, structure concept, system definition, payload integration, internal layout and weight, and balance computation.

3. Aerodynamic analysis (computational fluid dynamics (CFD)).

4. Flight performance analysis: including database establishment (aerodynamic, weight, and propulsion databases) and performance computations (integral performance, point performance-flight envelopes, and ground performance).

5. Structural analyses finite-element method (FEM) of the chosen configuration and aeroelastic considerations of the high aspect ratio/low mass wing.

6. Reliability, maintainability, and safety analysis.

\section{DESIGN PROCESS}

As most applications for stratospheric platforms require continuous operation, solar power seems to be the only adequate option to provide the necessary power for propulsion and for the payload. A power system consisting of solar cells and an energy storage system to bridge the night phases would therefore be required.

Solar power electric energy would be used in the project to drive the propellers for the required flight. It would use electric-motor-driven propellers to convert electrical power into thrust. Any electric energy not required for the propulsion and payload operations would be pumped back into the fuel cell energy storage system and, during the night, the platform would maintain altitude, thanks to the stored (solar) energy [6-8].

The power collected by the PV panels during the day would be absorbed not only by the electric motors in order to drive the platform but also by the control system and by the payload. The power that remains would feed the electrolyser, which would produce high-pressure hydrogen and oxygen from the stored water. The gases would be stored in separate cylinders and supply the fuel cells during the night, so that the electric power needed by the platform would always be assured. The system would be completed by a pump to feed the electrolyser with water, the gas tanks, the water tank, and some auxiliaries.

The regenerative fuel cell energy storage system would be used to balance the power. Although the power required to fly the aircraft is roughly constant over time, the power available from sunlight changes during the day - from zero at sunrise, to peak power at noon, and back to zero at sunset.

The amount of energy that would need to be stored overnight (energy storage system capacity) depends on the location (Earth latitude) and the time of year. In general, winter conditions and higher latitudes require more capacity because the nights are longer and there is less sunlight.

The key figures of merit are the storage system's energy density (watt-hours of energy stored per kilogram of storage system mass) and its efficiency. The high energy density that would be required to keep a solar airplane flying over most locations and during most times of the year has forced designers to consider more complicated forms of energy storage. Chief among these is the hydrogen/oxygen regenerative fuel cell (RFC); an energy storage system, based on dedicated proton exchange membrane fuel cells, gives an energy density of $450-600 \mathrm{Wh} / \mathrm{kg}$, with respect to $200-220 \mathrm{Wh} / \mathrm{kg}$ of the best lithium batteries, and efficiency of about 60 per cent. No other energy storage method (outside nuclear power) has a higher energy density.

Beginning in the early 1990s, significant investments from the automotive industry resulted in a seven-fold increase over a span of 5 years. Rapidly emerging hydrogen-based technologies, primarily derived from the automotive industry, could be used to start a new era of propulsion systems for light aircraft and small commuters and electrical system replacement for larger transport aircraft.

The feasibility of this project depends on several key-enabling technologies such as fuel cell stack, fuel cell system, hydrogen fuel storage, and a safe 
airport hydrogen-fuelling infrastructure. It is estimated that an almost ten-fold increase in energy density $(5 \mathrm{kWh} / \mathrm{kg})$ can be expected within ten years to enable the all-electric flight of small commercial aircraft.

Since today's solar cells only convert a small percentage of the sun's energy into useful work, any stratospheric platform needs a large surface area for power generation. The solar cell area does not impose a problem on aerostatic platforms due to their large surface provided by the lift gas hull. For aerodynamic configurations, the sun-powered level flight can only be obtained through a suitable design and accurate integration of the highest standards that can be achieved for each involved technological item: structure, aerodynamics, solar cells, energy storage, propulsion efficiency, and avionics

The theoretical efficiency limit of solar energy conversion under idealized conditions is 86 per cent. Present technology, however, limits this percentage to about 50 per cent. One of the most fundamental limitations on solar cell efficiency is the band gap of the semiconductor from which the cell is made. In order to obtain improvements, researchers and manufacturers stack different band gap materials in multi-junction cells. The maximum efficiency that can be achieved with a solar cell, made from a single material, when converting light to electrical power is about 30 per cent; the best efficiency that has actually been achieved is about 25 per cent. Many different layers could be stacked to catch photons at all energies, reaching a better efficiency than 70 per cent (the best efficiency actually achieved with multi-junction solar in only a few research projects is about 35 per cent).

The two most common types of semiconductor materials used in PV cell manufacturing are silicon (Si) and gallium arsenide (GaAs).

Most commercial solar cells used in terrestrial applications are made from wafers of silicon. About 85 per cent of the PV market consists of Si solar cells. When used in commercial production, they allow power conversion efficiency close to 17 per cent. These thick $(200-300 \mu \mathrm{m})$ single-crystal silicon cells are today available at low prices (about $700-1000 € / \mathrm{m}^{2}$ ). Higher efficiency (up to 25 per cent) very thin $(50-70 \mu \mathrm{m})$ gallium arsenide cells are also available, although at a higher price (about $25.000 € / \mathrm{m}^{2}$ ).

Since the solar cell efficiency closely depends on the surface temperature of the PV array, a low operational temperature of the solar cell is beneficial. For this application, the ambient temperature is an important parameter, because the estimated temperature at the flying level $(17 \mathrm{~km})$ is about $55^{\circ} \mathrm{C}$, but the solar cells specification are given for the cell temperature of $+28^{\circ} \mathrm{C}$ (standard test conditions).
Good efficiency could be obtained through the proper design of the electric brushless motor (95 per cent) and of the propellers (85 per cent), which have a high diameter and a speed of about a $1000 \mathrm{~min}$; these elements should be designed to fulfil the requirements of low mass and high reliability [15]. Particular attention should be paid to the automation of the full propulsive system; furthermore, the power that is available from the sun should be properly split between the motors and energy storage system.

A multi-disciplinary optimisation computer program has been developed to design the platform, taking into account wind speed up to an altitude of $27 \mathrm{~km}$, the solar radiation changes over a period of 1 year, altitude, latitude, solar cell efficiency and weight, fuel cell efficiency and energy density, aerodynamic profile drag, etc. The preliminary design of a Solar HALE Aircraft Multi Payload and Operation (SHAMPO) (Fig. 6) flying at high altitude and low Reynolds numbers, has led to the main features reported in Table 1.

\section{INTERNAL AND EXTERNAL LAYOUT}

The power system of a stratospheric platform consists of the three main subsystems:

(a) power source;

(b) energy storage;

(c) electrical propulsion system.

which should be managed by an electronic control system to make optimum use of the available energy. The architectural analysis and design of the power conditioning (DC/DC converter) system for the fuel cells, the solar power supply and the propulsion system (motor and inverter) interface of the platform has been performed with the assistance of numerical simulation [16].

The PV energy source module converts the solar energy into electrical energy and provides it to the DC link in a suitable way. The module consists of the solar cells, the DC/DC converter, and the maximum power point tracker (MPPT) controller. The MPPT controller and the DC/DC are used to obtain the maximum power from the solar cells.

The FC energy storage module acts as an energy storage system. It consists of the fuel cell array, the hydrolyser and the hydrogen, oxygen, and water tanks. The gases are stored at high pressure (120250 bar) and used during the night to feed the fuel cells that supply the motors; the water feeds the electrolyser to close the cycle.

The electric motor module, consisting of the electric motor and the inverter, converts electrical energy into mechanical energy. 
Table 1 The main characteristics of SHAMPO

\begin{tabular}{lll}
\hline Description & Symbol & Value \\
\hline Flight altitude & $Z$ & $17000 \mathrm{~m}$ \\
$\begin{array}{l}\text { Maximum power available for } \\
\text { payload }\end{array}$ & $P_{\mathrm{PL}}$ & $1300 \mathrm{~W}$ \\
Avionic mass & $W_{\mathrm{AV}}$ & $32 \mathrm{~kg}$ \\
Maximum payload mass & $W_{\mathrm{PL}}$ & $130 \mathrm{~kg}$ \\
Structural mass & $W_{\mathrm{STR}}$ & $430 \mathrm{~kg}$ \\
Solar cell mass & $W_{\mathrm{SC}}$ & $127 \mathrm{~kg}$ \\
Take-off weight & $W_{\mathrm{TO}}$ & $924 \mathrm{~kg}$ \\
Power available for the avionic & $P_{\mathrm{AV}}$ & $325 \mathrm{~W}$ \\
Cruise flight Power supplied to the & $P_{\mathrm{FLY}}$ & $6700 \mathrm{~W}$ \\
$\quad$ electric motors & & \\
Sun power (38 ${ }^{\circ} \mathrm{N}$ April) & $P_{\mathrm{SUN}}$ & $11560 \mathrm{~W}$ \\
Efficiency energy storage system & $\eta_{\mathrm{FC}}$ & 0.6 \\
$\quad$ Fuel cell + A1) & & \\
Density energy storage system & $W_{\mathrm{FC}}$ & $550 \mathrm{Wh} / \mathrm{kg}$ \\
$\quad$ Fuel cell + A1) & & \\
Efficiency solar cells & $\eta_{\mathrm{SC}}$ & 0.21 \\
Density solar cells & $W_{\mathrm{SC}}$ & $0.6 \mathrm{~kg} / \mathrm{m}{ }^{2}$ \\
Efficiency electric motor & $\eta_{\mathrm{M}}$ & 0.95 \\
Efficiency propeller & $\eta_{\mathrm{PROP}}$ & 0.85 \\
Number of motors & $N$ & 8 \\
Cruise airspeed & TAS & $25 \mathrm{~m} / \mathrm{s}$ \\
\hline
\end{tabular}

The mixed supply System, with solar cells and fuel cells, requires a common DC link in order to adjust the voltage level between the different sources. Solar cells have the additional requirement of load impedance adjustment to allow the maximum power point to vary according to the ambient conditions, like temperature or solar irradiance.

The core of the full scale HeliPlat Power Supply Drive (PoSuDri) should be based on a DC link of $360 \mathrm{~V}$. This voltage has been chosen as a balanced value in order to limit the size and weight of the electric cables, which in the present design of the solar aircraft must supply power over a $70 \mathrm{~m}$ length of wingspan. Therefore, all electrically powered subsystems become part of the electric power distribution system, which unites all the electrical sources and loads of the aircraft by means of the high voltage power distribution bus. A three-dimensional CAD model of the preliminary internal layout has been set up using CATIA V5 (Fig. 6a).

A blended wing body (BWB) configuration with eight brushless electric motors has been chosen as a result of the preliminary study. The weight of each motor is about $6.5 \mathrm{Kg}$, including the carbonfibre propeller blade.

The BWB solution, compared to the conventional design [6-12], seems to be the best compromise between performance, available surface for solar-cells and volume for multi-payload purposes; the fuselage blended zone in fact presents a volume of about $38 \mathrm{~m}^{3}$.

The Heliplat propeller blade (blade radius $=1.15 \mathrm{~m}$ ), [6-8], has been used for the preliminary design of SHAMPO. Propeller characteristics are obtained using two in-house FORTRAN developed tools. The first tool is able to compute the maximum efficiency propeller geometrical characteristics giving as input the design condition, blade number, and airfoils databases. The output of the first tool are the chord and pitch distributions. The second tool gives performances in terms of efficiency, thrust coefficient, and torque coefficient and are used to evaluate the characteristic far from the design point.

The thrust supplied by this propeller in cruise conditions is sufficient for the SHAMPO design point (Fig. 7), and it is possible to increase the airspeed by using the $5000 \mathrm{~W}$ of surplus power available for $2 \mathrm{~h}$.

A flight power of about $6700 \mathrm{~W}$ supplied to the electric motors have been computed in cruise conditions $\left(Z=17000 \mathrm{~m}\right.$, 1st April $\left.38^{\circ} \mathrm{N}\right)$ flying at $25 \mathrm{~m} / \mathrm{s}$; supplying a maximum available power of about $9800 \mathrm{~W}$, to the motors the airplane could reach $31 \mathrm{~m} / \mathrm{s}$ and in the case of emergency or to contrast wind jet-streams, it would be able to reach $36 \mathrm{~m} / \mathrm{s}$, using $5000 \mathrm{~W}$ reserve power.

Rolling control on SHAMPO is accomplished by using ailerons located on the outboard section of the wing. The restrictions imposed by roll control for general aviation aircraft are not severe [17-19]. The
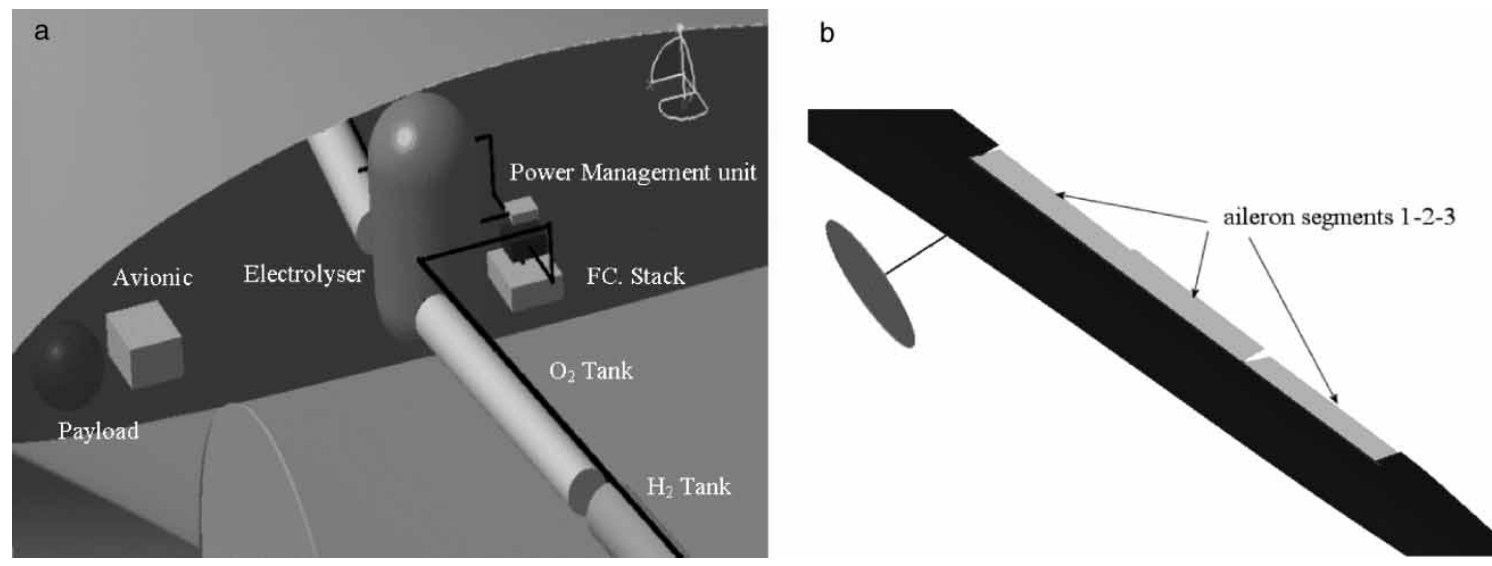

Fig. 6 Aileron segments and internal layout 


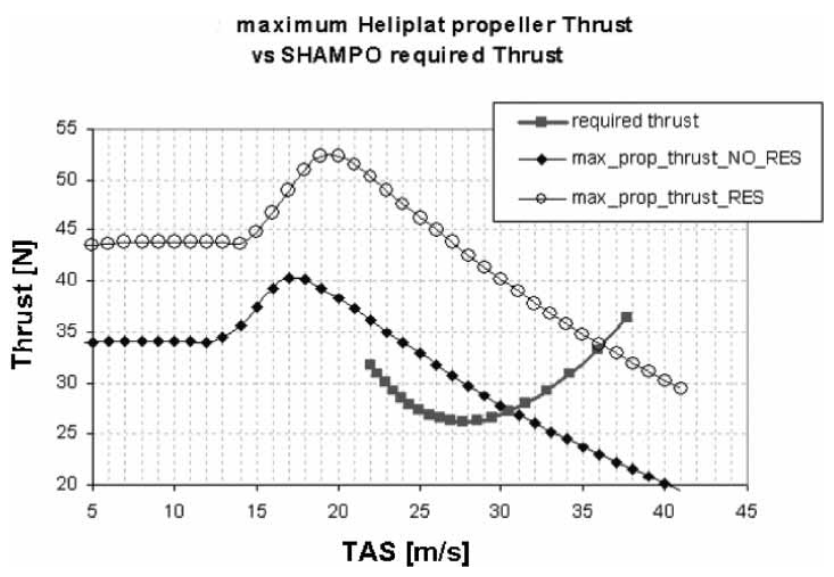

Fig. 7 Propeller thrust versus required thrust

ailerons are positioned along the wing span at a distance of 18.8 to $30.8 \mathrm{~m}$, and the total surface is subdivided into three parts (Fig. 6b), each one controlled by an electric motor in order to have a triple redundancy system. The control surfaces have been introduced in the Vsaero CFD aerodynamic model. The input file has therefore been modified to take into account several rotations of the control surfaces.

The CATIA V5 external layout (Fig. 8) has also been developed and used for aerodynamic and structural analysis models and to estimate the aerodynamic derivatives.

The main geometrical characteristics of the final configuration are:

$b_{\mathrm{w}}=73 \mathrm{~m} ; \quad S_{\mathrm{w}}=192 \mathrm{~m}^{2} ; \quad A R_{\mathrm{w}}=28 ; \quad \mathrm{c}_{\text {mean }}$ $=3.89 \mathrm{~m} ; \quad \Lambda_{\mathrm{w}}=5^{\circ} ; \quad \mathrm{b}_{\mathrm{ht}}=12 \mathrm{~m} ; \quad S_{\mathrm{ht}}=25 \mathrm{~m}^{2}$; $A R_{\mathrm{ht}}=5.76$; and $\Lambda_{\mathrm{ht}}=8.8^{\circ}$.

\section{AERODYNAMIC ANALYSIS (CFD)}

The design procedure that has been followed in the preliminary analysis is based on the energy balance

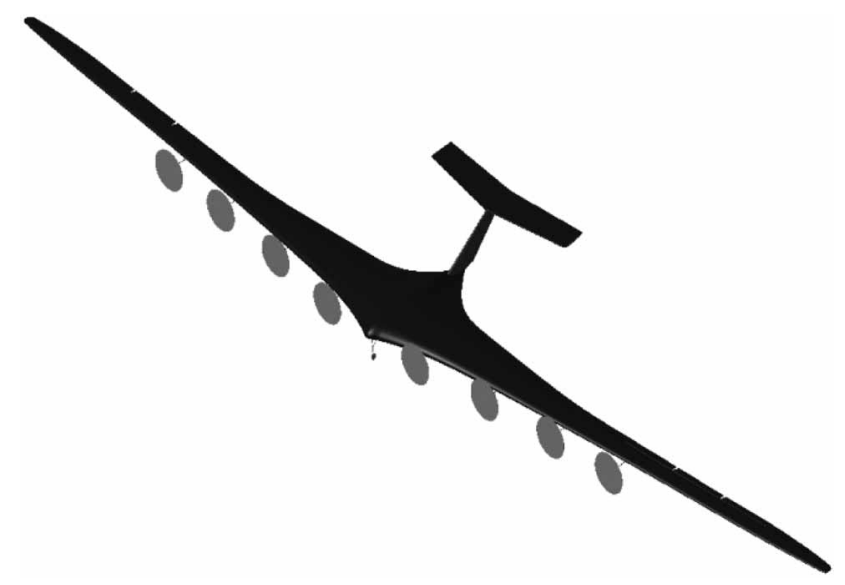

Fig. 8 Shampo configuration, external view equilibrium between the available solar power and the required power, the former being dependent on the solar cell area installed on the wing and stabilizer, the latter depending on the velocity and total drag of the platform.

The power required, per unit wing area, $\left(P_{\text {req }} / S_{\mathrm{w}}\right)$ to maintain horizontal flight is given by

$$
\frac{P_{\text {req }} / S_{\mathrm{w}}=(2 / \rho)^{0.5}\left(W_{\text {tot }} / S_{\mathrm{w}}\right)^{3 / 2}\left(C_{\mathrm{D}} / C_{\mathrm{L}}^{3 / 2}\right)}{\eta_{\text {prop }}}
$$

where the propulsion efficiency $\eta_{\text {prop }}$ includes propeller, motor, and inverter efficiency.

The endurance parameter has in particular to be satisfied to minimize the power required for a horizontal flight. When minimizing the parameter $C_{\mathrm{D}} / C_{\mathrm{L}}^{3 / 2}$, it has also been preferred to reduce the drag coefficient $C_{\mathrm{D}}$ instead of only increasing the lift coefficient $C_{\mathrm{L}}$, because of the lower structural load. The total drag coefficient is obtained from the sum of the wing and tail profile drag, the wing and tail induced drag and the parasite drag (fuselage, booms, hard interaction with wing and tails). Reynolds numbers of less than 700000 should be considered in most cases.

The aerodynamic calculations were made using the VSAERO code [20], a computer program used to calculate the non-linear aerodynamic characteristics of arbitrary configurations in a subsonic flow. Non-linear effects of wake shape are treated in an iterative wake relaxation procedure, and the effects of viscosity are treated in an iterative loop, while coupling the potential flow and integral boundary layer calculations.

The aircraft configuration has been changed during the design process. The first unswept blended configuration, which was worked out during the first iteration, presented some problems from the longitudinal stability point of view. In order to move the center of gravity forward, with the constrains of installation volumes, a classical solution with a fuselage has been tested. This solution was later discarded because it was too penalizing in terms of aerodynamic efficiency.

To increase the stability margin without any significant aerodynamic efficiency reduction, a wing without fuselage and with a small angle of sweep (about $5^{\circ}$ ) has been chosen in order to have a static margin of about 9-10 per cent.

A second investigation has been then performed, with a wing sweep angle of $5^{\circ}$, to optimize the wing airfoils and the shape of the tip, with the aim of reducing the contribution of the induced drag.

The main factor responsible for total platform coefficient drag (0.0266 at a $6^{\circ}$ angle of attack) is the wing and in particular the outer part. Induced drag corresponds to about 63 per cent of the total 


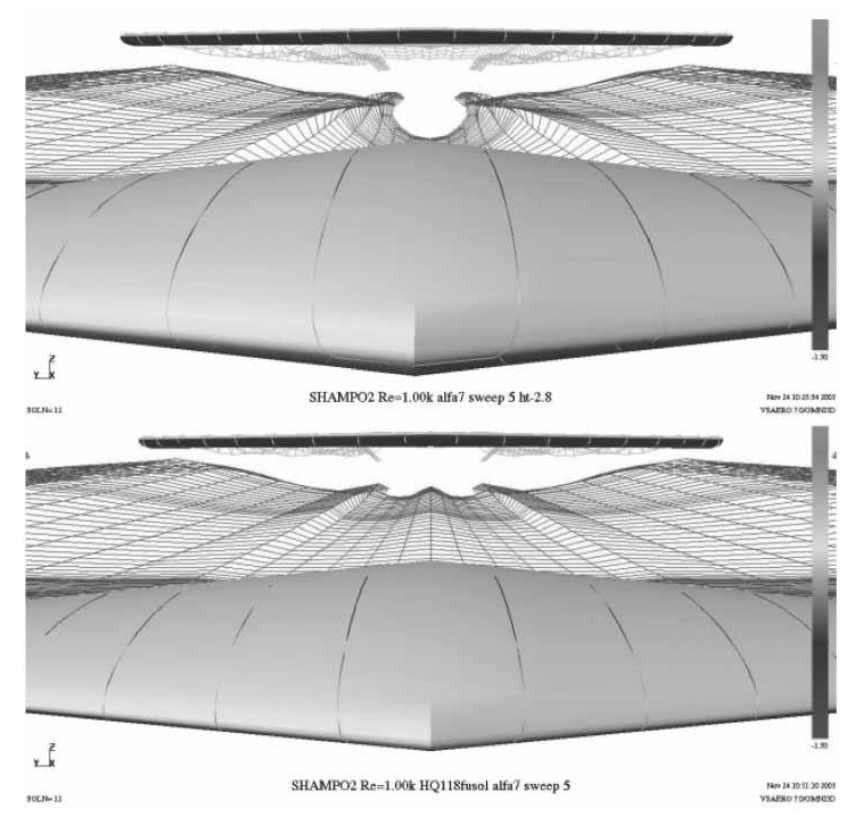

Fig. 9 Downwash blended zone

drag, whereas viscous drag accounts for 24 per cent and pressure drag for 13 per cent.

The use of a round wing tip appears to have a positive role in minimizing tip vortex formation and thus minimizing induced drag.

When using the same airfoil DAE21 for the wing and blended fuselage part, a large zone of depression, which was responsible for performances losses, is formed behind the wing. For this reason, new SH118 profiles, which are capable of improving the pressure recovery in the fuselage zone, have been developed; with this airfoil, the wake leaves the body in a more uniform way (Fig. 9), reducing downwash in the blended zone.

This configuration presents a maximum efficiency of about 41.6 at $C_{\mathrm{L}}=0.85$ (Fig. 10) and a maximum endurance parameter of about 43 at $C_{\mathrm{L}}=1.2$. The

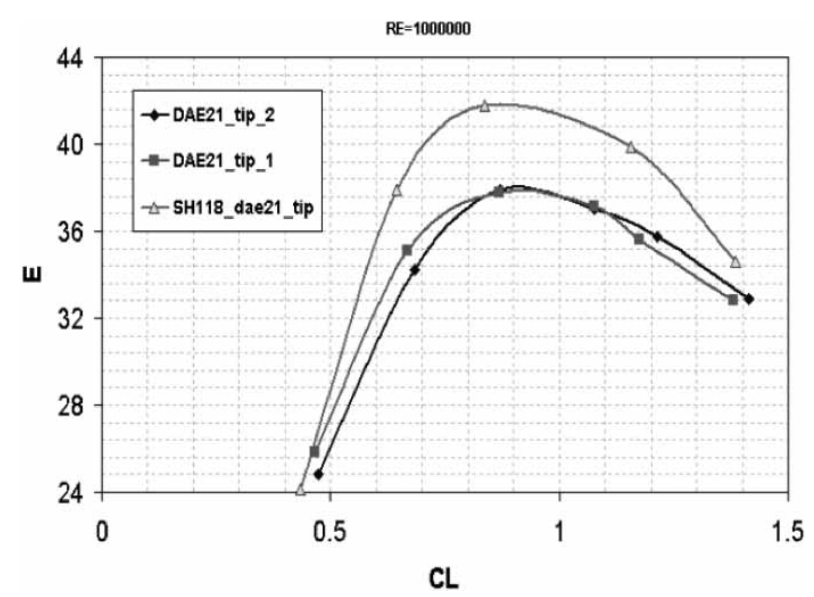

Fig. 10 Aerodynamic efficiency

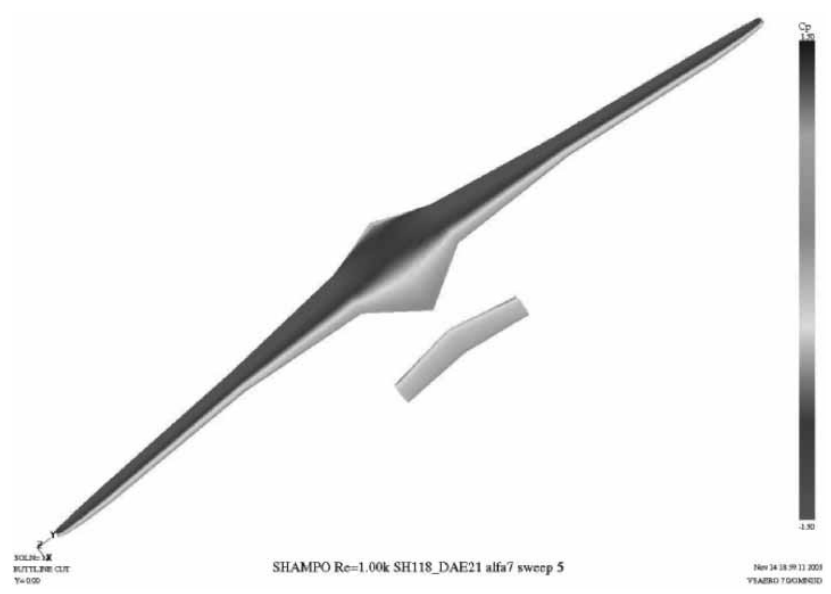

Fig. 11 Upper surface pressure distribution at $7^{\circ}$ angle of attack

lift and pressure distribution along the wing span has also been computed (Fig. 11).

The configuration also presents a good stability margin of about 10 per cent of the mean aerodynamic chord. This configuration has been chosen as a starting point for the structural design.

\section{FLIGHT PERFORMANCE}

A multidisciplinary design to determine the static and dynamic behaviour of an aircraft in the early stage can lead to significant weight and cost saving and improvement in configuration and performance $[\mathbf{6}-\mathbf{8}, \mathbf{1 2}]$. The computational fluid dynamics solver (VSAERO CFD) has been used to directly calculate the stability and control derivatives of the new SHAMPO configuration. The CFD forces and moments have been differentiated with respect to the angle of attack, angle of sideslip, and aircraft shape parameters in order to determine these derivatives. A complete database of the main static and dynamic derivatives were worked out using this method.

The developed VSAERO model has a wing and horizontal tail, but lacks a vertical tail, therefore classical formulas have been used [17-19]. The effect of a roll angular velocity on the pressure distribution and wake shape is shown in Fig. 12.

Aircraft flying qualities and stability requirements are defined from many sources. The requirements for longitudinal static stability simply require that the pitching moment at zero-lift angle of attack, $\mathrm{Cm}_{0}$, should be positive and that the derivative of the pitching moment with respect to the angle of attack, $\mathrm{Cm}_{\alpha}$, must be negative. These two requirements are mainly determined by the wing configuration. The new SHAMPO configuration satisfied both conditions. 


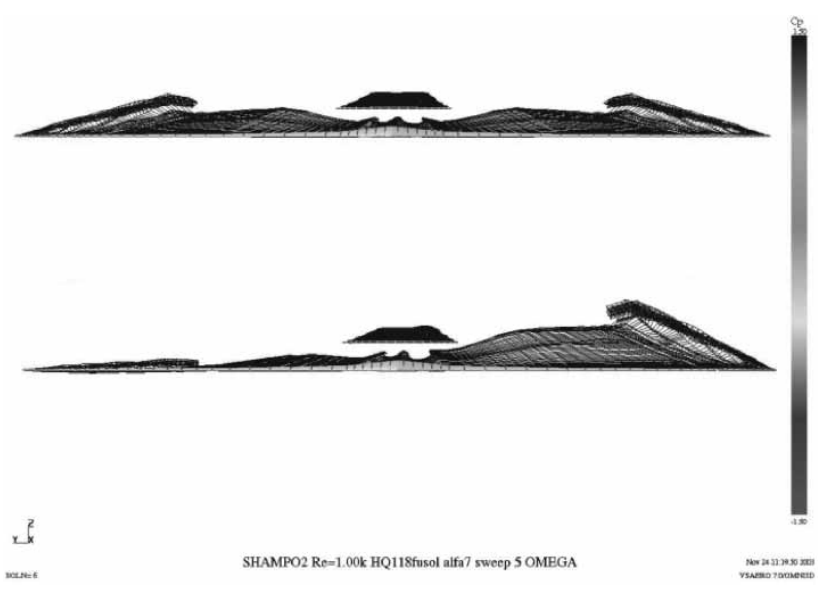

Fig. 12 Effect of roll angular velocity

Similar to the longitudinal stability requirements, lateral-directional stability is based on both static and dynamic requirements. For static stability, the aircraft's yaw stiffness, $C_{\mathrm{n} \beta}$, should be positive and its roll stiffness, $C_{\mathrm{l} \beta}$, should be negative. These requirements ensure that the aircraft generates a positive yawing moment and a negative rolling moment for a positive sideslip, and it can thus stay in controllable flight conditions. From a first estimation of the SHAMPO derivatives, considering a value of natural dihedral of $2.7^{\circ}$, the static condition has been verified with the calculated values $\mathrm{C}_{\mathrm{n} \beta}=0.012 \mathrm{C}_{\mathrm{l} \beta}=-0.083$.

A flight dynamic analysis has been performed, in the preliminary design phase, considering that rigid-body degrees of freedom and elastic degrees of freedom are decoupled; however, this is not always possible. The frequency separation between the rigid-body motions and elastic degrees of freedom for advanced aircraft (such as solar UAV, very light weight UAV or advanced aircraft with active control systems) may not be sufficient to permit the typical treatment of the vehicle dynamics. In particular for flexible HALE-UAV, it is not always safe to treat rigid body effects and flexibility effects separately as demonstrated by the Helios prototype mishap.

The intention of this preliminary stage has been to have a first estimation of the airplane handling qualities and a rigid mathematical model has been therefore used to describe the flight dynamics of the aircraft.

MIL-F-8785C contains a number of criteria with which the modes of a piloted aircraft can be compared to predict the expected flying quality levels. The closest comparison category, for the SHAMPOUAV, could be that of a small light aircraft, which is a Class I category aircraft. The approach used to analyse the dynamic behaviour of the airplane has been of using the uncoupled, linearized equations of motion solutions. A Matlab-Simulink [21] flight dynamic software has been used to obtain the equations.

All the longitudinal modes are stable for the SHAMPO-UAV cruise condition. With reference to the short period criteria within MIL-F-8785C, for the Category B Flight phase, a minimum damping ratio of 0.2 is obtained for Level 2 and a limit of 0.15 for Level 3. The SHAMPO UAV longitudinal damping is 0.203 .

There are two aperiodic modes (one stable and one unstable) and one stable periodic mode for the SHAMPO-UAV cruise condition in the lateral motion.

The Dutch roll is a coupled oscillation between yaw/sideslip and roll, a complex mode usually determined by the characteristics of the rolling and yawing moments with sideslip. The Dutch roll mode is stable, in SHAMPO-UAV, with reference to MIL-F-8785C. The roll-mode flying quality criteria are also well within the specified requirements given in MIL-F-8785C.

The remaining mode, the spiral mode, has already been established as being unstable. A certain degree of spiral instability can be accepted for different flying quality levels. For Level 1 Cat B, a time-todouble amplitude greater than $20 \mathrm{~s}$ is acceptable according to MIL-F-8785C. SHAMPO-UAV has a value of time-to-double amplitude of about $45 \mathrm{~s}$.

It can be concluded that the aircraft is statically stable and that it is able to stabilize longitudinal oscillations on its own; it has a spiral instability with a time-to-double amplitude that is however acceptable.

\section{STRUCTURAL CONCEPTS AND ANALYSES}

A preliminary structural concept was defined according to the estimated inertial and aerodynamic loads. High structural efficiency is required to minimize the airframe weight and increase the payload mass. This is obtained through:

(a) extensive use of high modulus graphite/epoxy material to obtain a very light-high stiffened structure with good aeroelasticity behaviour;

(b) numerical structural analysis using the FEM.

In spite of the weight reduction, in high aspect ratio wings like VESPAA, aeroelastic phenomena play an important role that has to be satisfied and verified.

The total platform weight, per wing area, is determined by adding the weight of the propulsion, the solar cells, avionics and payload to the airframe; the weight of the propulsion system includes 
brushless motors, inverter, conditioning system, and propellers.

For the adopted configuration, a good structural wing solution to enhance the bending stiffness could be represented by an opportunely reinforced high modulus carbon fibre leading edge wing-box (Fig. 13). The main spar could be subdivided into five parts, which could be connected to each other by metal fittings.

The aero-structural loads, including both manoeuvre and gust, have been defined according to the JAR-VLA 333 airworthiness regulations, with a maximum limit load $n=3$ for the diving speed.

A computer program has been developed to evaluate and define the structural characteristics of the main wing/tail spars of the platform considering strains under the value of $1000 \mu \varepsilon$ for all flight limit loads. Different materials and layouts have been considered in order to introduce a level of optimization to the iterative calculations. CFRP data have been introduced referring to a Young's modulus in the fibre direction of about $275 \mathrm{GPa}$, ultimate compressive strain limit of about $1500 \mu \varepsilon$, a lamina thickness of $0.135 \mathrm{~mm}$ and a density of $1580 \mathrm{~kg} / \mathrm{m}^{3}$. The inertial loads (structural and non structural) have been estimated and taken into account according to the preliminary configuration design. The ultimate strain behaviour along the wing span is reported in Fig. 14.

An FE model of the SHAMPO main spar configuration has been developed at the preliminary stage using the Patran/Nastran code, based on preliminary design structural concept. The model consists of one half-wing, which is considered clamped in the symmetry plane. The leading-edge wing-box was simulated using shell elements (Quad4). The mesh on these surfaces has been made respecting the exact radial and longitudinal position of the ply lay-up, which has been determined with the preliminary

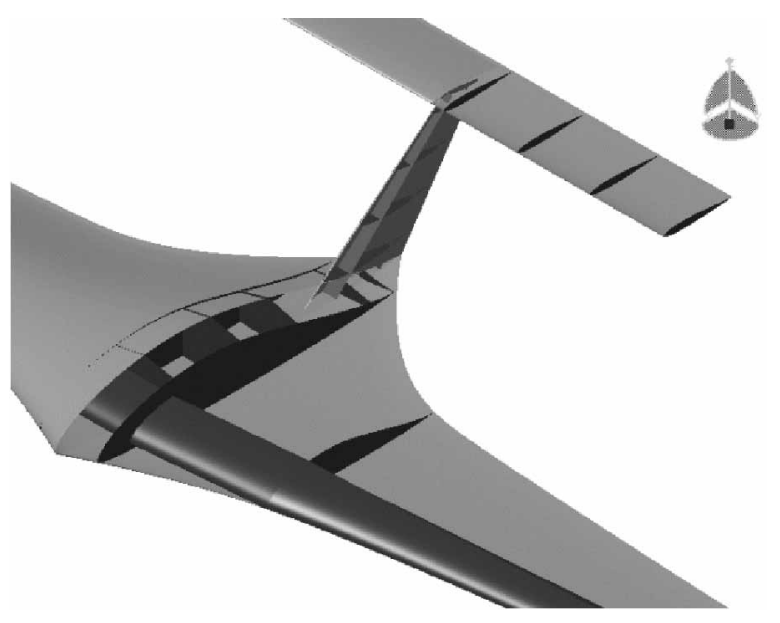

Fig. 13 Structural configuration

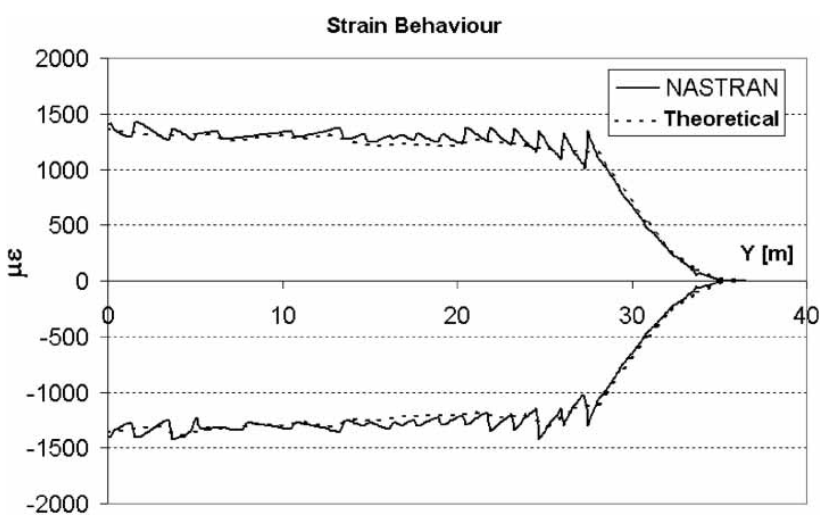

Fig. 14 Strain behaviour along wing span

design structure program. The load distribution has been determined from an estimated lift and mass distribution according to the preliminary data and aerodynamic calculations in order to obtain an equivalent load condition. The load condition reported in this work only concerns the $\mathrm{D}$ point of the flight envelope ( $n=3, \mathrm{~V}_{\mathrm{EAS}}=47 \mathrm{~km} / \mathrm{h}$, according to airworthiness regulation). A comparison between the theoretical and Nastran results is reported in terms of ultimate strains (Fig. 14). A new and improved FE model of the entire SHAMPO airframe has been developed, in order to evaluate the structural behaviour of the whole optimized SHAMPO configuration (Fig. 15). The structure has been designed to have a very stiff low weight airframe. Wing and horizontal tail spars have different lay-up $\left( \pm 20^{\circ} / 0_{\mathrm{n}}^{\circ} / \pm 45^{\circ} / \text { core }\right)_{\mathrm{s}}$ along the span in order to minimize the weight of the structure while ribs, for modelling simplicity, are considered all made by the same material with the same lay-up. The conformal fuselage also had a variable lay-up. The results of the FE model showed a wing weight (wing-box and ribs) of about $314 \mathrm{~kg}$; the fuselage weight of about $58 \mathrm{~kg}$, and there was a total airframe weight without skin of $412 \mathrm{~kg}$. These results are in a good agreement with weight estimation formulas for man-powered airplanes, high-altitude airplanes, or ultra-light cantilever twin-boom tails. Some FE results are displayed in Fig. 15; a maximum deflection of about $6 \mathrm{~m}$ at the tip of the wing has been determined at point $\mathrm{D}$ in the $\mathrm{n}-\mathrm{V}$ diagram, considering a safety factor of $1.5(N=4.5)$. No particular stress concentration has been revealed.

\section{AEROELASTIC CONSIDERATIONS}

A preliminary aeroelastic analysis has been carried out on SHAMPO UAV. The first preliminary model consisted of a beam-wise structure of one half-wing considered clamped in the symmetry plane, 

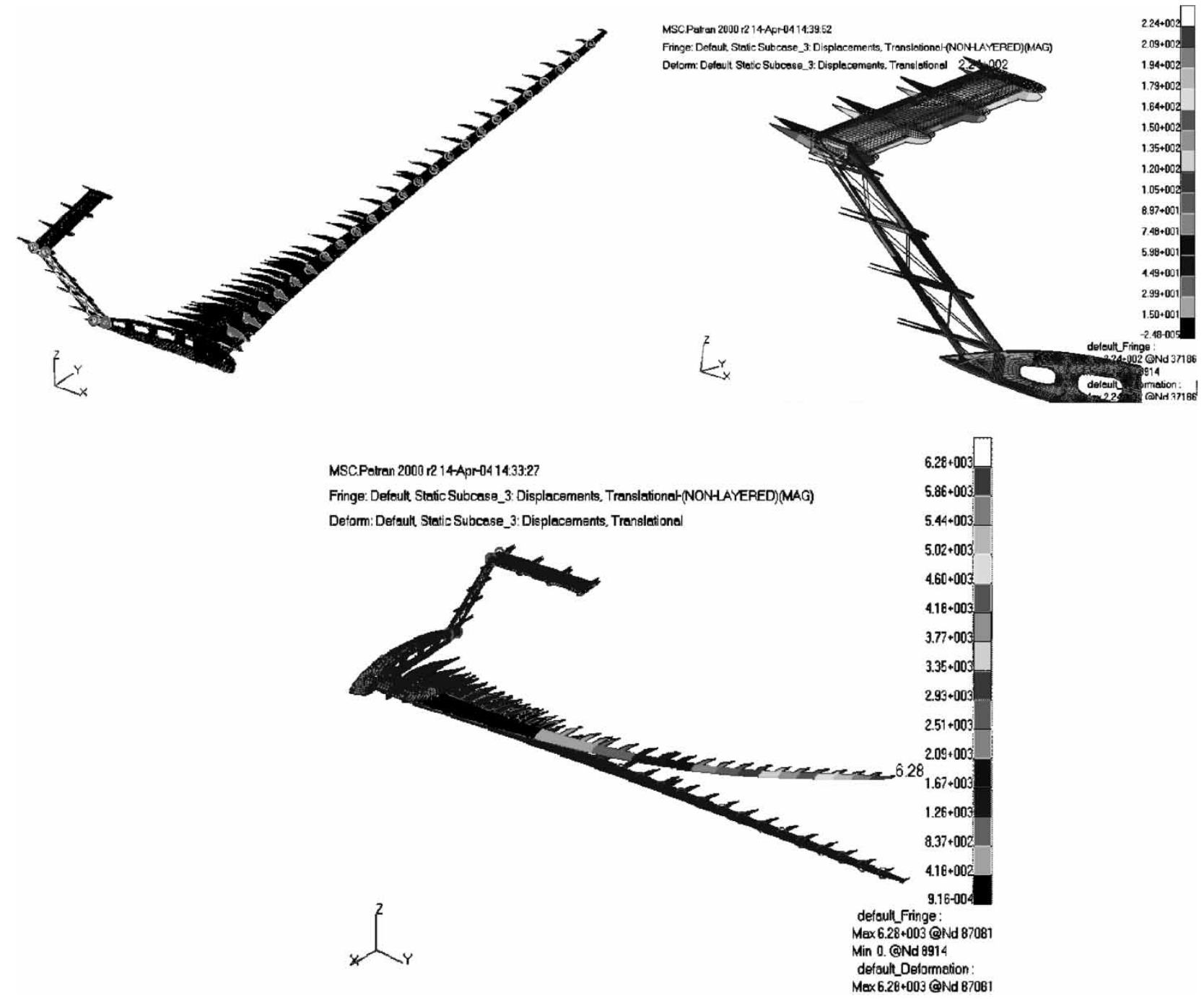

Fig. 15 FE model and wing and tails deflection

positioned along wing-box elastic axis as determined in section 8 . The stiffness and inertia properties have been introduced, according to the preliminary structural design concepts.

The motors, fuel cell system, payload, and vessels have been considered as concentrated masses with estimated properties, according to the preliminary layout. The other non-structural masses have been distributed along a beam wise rear spar with only an inertial effect. No specific structural details have been introduced into the model, such as junctions or rotating propellers. The aerodynamic wing loads have been defined according to the strip theory and the Theodorsen function [22].

In this preliminary analysis, the flutter calculation has been performed considering an undeformed equilibrium condition; typical V-g plots have been obtained and critical velocities have been determined as the damping parameters tend to be positive (Fig. 16(d)). No structural damping or other external damping has been introduced. Some of the linear wing modes considered in its un-deformed equilibrium state are also plotted (Figs 16(a) to (c)).

No critical speeds have been detected up to $100 \mathrm{~m} / \mathrm{s}$ using the linear calculation. Compared to the design diving speed, reported in previous sections, it is possible to conclude that the airworthiness target is satisfied by the proposed configuration. Moreover, when the airplane shows a highly flexible wing, an advanced aeroelastic behaviour should be considered as stated in references [13], [23], and [24]. Moderate-to-large bending deflections, due to aerodynamic loads, cause non-linear coupling between edge-wise bending and torsion. Therefore, the trim condition and the natural frequencies of flight dynamics could be significantly affected by the inherent flexibility and non-linear deformations of the wing structure, leading to an overall change in the wing's aeroelastic characteristics $[\mathbf{2 3}, \mathbf{2 5}]$. 


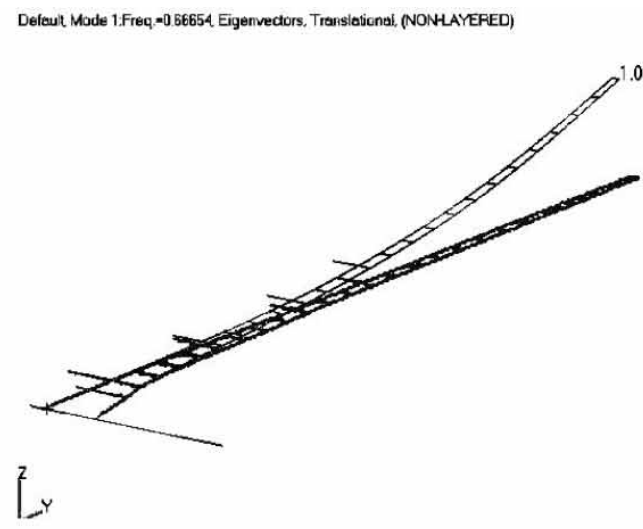

(a) - $1^{\text {st }}$ flap linear mode

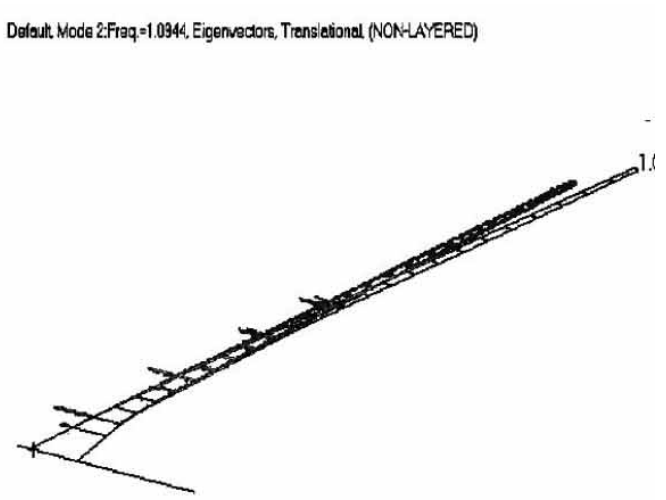

(b) - $1^{\text {st }}$ lag linear mode

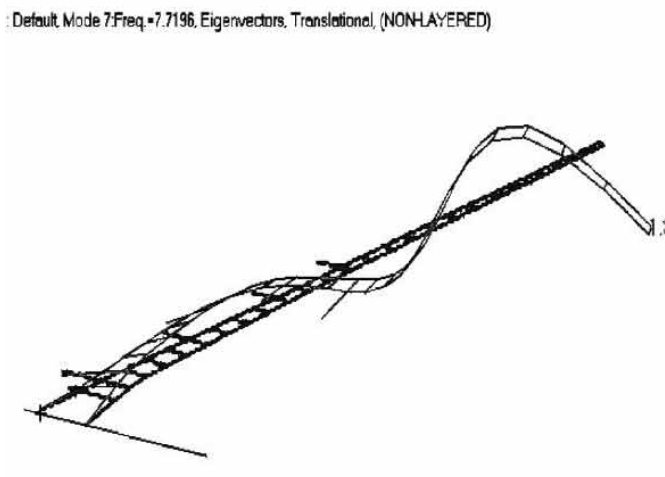

(c) $-1^{\text {st }}$ torsional linear mode

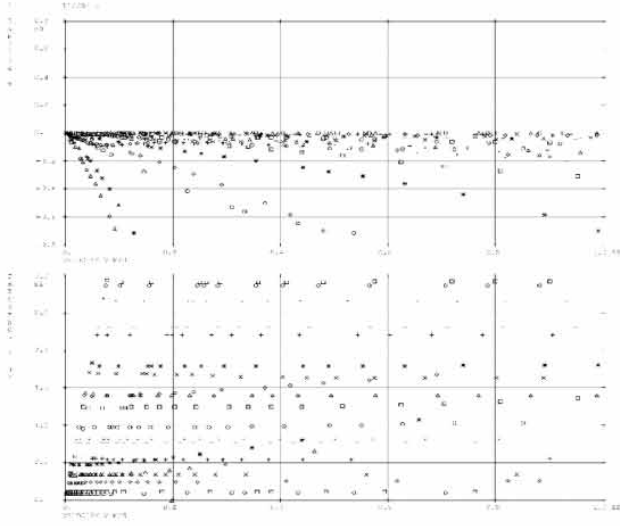

(d) V-g Plot

Fig. 16 Linear natural modes and flutter identification

A non-linear aeroelastic model has been developed and proposed as a design/diagnostic analysis tool $[\mathbf{2 4}, \mathbf{2 5}]$. A geometrically consistent non-linear structural model for large deformations, developed by Hodges and Dowell [26] and modified according to Da Silva's second-order geometrical non-linear terms [27], has been implemented. The structural model has been coupled to an unsteady aerodynamic model for an incompressible flow field, based on the Wagner aerodynamic indicial function, in order to obtain a non-linear aeroelastic model [28]. Linear and non-linear static and dynamic aeroelastic responses have been considered.

The introduction of a small dynamic perturbation about a non-linear static equilibrium has been applied in order to solve the system of governing equations and to study the sub-critical and supercritical aeroelastic response and the flutter boundaries. The in-plane, out-of-plane, and torsional displacements have been considered to be a summation of the static and dynamic components in the un-deformed reference system.
The partial differential equations governing the dynamics of the flexible beam, were reduced to a system of ordinary differential equations $[\mathbf{2 4 , 2 5}$, 29] using a series discretization technique [30], along with Galerkin's method, to obtain the aeroelastic governing equations. Galerkin's shape functions have been chosen from a set of linearly independent and complete functions derived from a clamped-free beam case.

The deflected equilibrium condition has also been affected by a change in the overall flight dynamic characteristics of the aircraft due to wing flexibility. It has been possible to implement the procedure in a preliminary aeroelastic evaluation as the nonlinear equilibrium system has been included in the analysis: the actual static deflection has to be connected to a specific flight condition. If, for example, we consider that at each speed a level flight condition has to be satisfied, the flutter speed and frequency are obtained with the subsequent main steps: (a) choosing a flight speed and the correct angle of attack to satisfy the vertical equilibrium condition, (b) calculating the static equilibrium deformed shape at the 
flight speed, (c) linearizing around the deformed shape, (d) calculating the eigenvalues of the linearized system, and (e) checking for stability. If the flutter speed and frequency are stable, increase the flight speed and repeat all the preceding steps until instability speed is reached.

The flutter speed and frequency are defined as the lowest airspeed and corresponding frequency at which a given structure flying in a specific atmosphere will exhibit sustained simple harmonic oscillations [22]. The flutter condition is a borderline situation, or neutral stability, due to the fact that small motions must be stable at a speed below flutter speed, whereas divergent oscillations occur in a range of speed above flutter speed.

Using the in-house developed tool linear flutter speed can be computed assuming the equilibrium static configuration as zero with no coupling effect. Including equilibrium terms, non-linear flutter speed calculations can be performed. Results on a typical HALE configuration are reported in references [24], [25], and [29] showing the flutter speed behaviour closely depends on tip deflection. With a static tip displacement of $1 \mathrm{~m}$, the nonlinear flutter speed reduces to 70 per cent of that obtained in the un-deformed equilibrium condition, while for a $w_{\text {tip }}$ of $2.5 \mathrm{~m}$ a flutter speed reduction of about 42 per cent respect to linear flutter has been obtained.

Another design indication that should be taken into account $[\mathbf{1 3}, \mathbf{2 3}, \mathbf{2 5}]$ is that the stiffness ratio between in-plane stiffness and out-of-plane stiffness could play an important role in increasing the flutter boundaries; the positive effect of increased flutter speed when a higher value of the stiffness ratio is introduced into the airplane structure design has been pointed out $[23,25]$.

Stiffness characteristics are determined according to an equivalent Euler-Bernoulli beam. Other extended models [31] are under development in order to have a better structural approximation.
The linear flutter results imply that small disturbances will grow exponentially for velocities higher than the flutter speed. However, as the amplitude of oscillations grows and additional non-linear stiffness is introduced, the vibrations do not grow to infinity but instead converge to a limit cycle oscillation (LCO). The amplitude of the LCO gives an idea of the amount of stress/strain on the structure and its study could be useful for analysis and design. Whether such non-linear effects are favourable or not will greatly depend on the particular circumstances and physical parameters that are involved. Nevertheless, it is clear that non-linear effects often lead to LCOs. In their absence, the alternative would be a catastrophic flutter and consequently structural failure.

The amplitude of the LCO can only be determined by time-marching the non-linear governing equations of the aeroelastic system, while the LCO stability can be done via a Lyapunov-based approach [28].

An example of supercritical aeroelastic behaviour (out-of plane tip-deflection $w_{\text {tip }}$ ), detected above the non-linear flutter speed has been obtained considering a small initial disturbance and by analysing the response via a time marching integration scheme, as reported in Fig. 17; the non-linear Mathematica ${ }^{\circledR}$ solver has been used.

Traditionally, flying aircraft have been treated within the confines of flight dynamics which, in most cases, deals with rigid aircraft. On the other hand, flexible aircraft fall into the domain of aeroelasticity. Although some attempts have been made to include aircraft rigid body degrees of freedom, aeroelasticity is concerned mostly with the vibration and flutter instability of wings fixed at the root. In reality, all aircraft possess some measure of flexibility and carry out rigid body manoeuvres, so that the question arises as to whether flexibility can be considered in the real aircraft flight dynamics behaviour
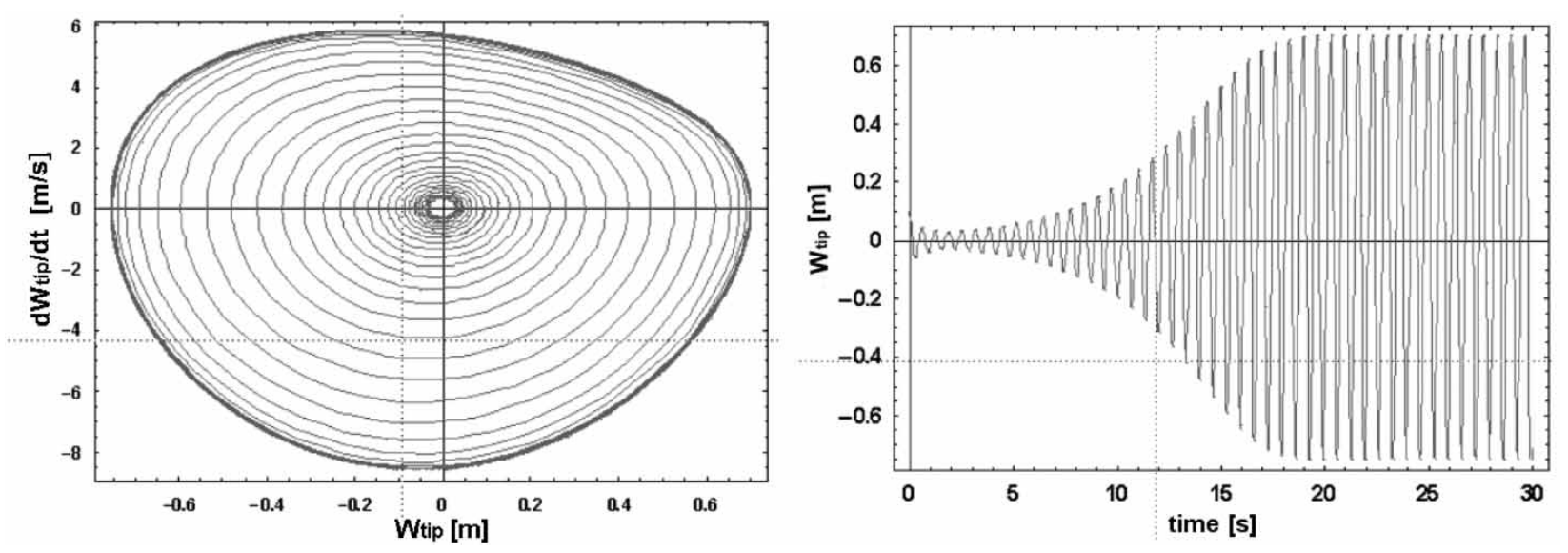

Fig. 17 Limit cycle oscillations (LCO) in the supercritical regime 
and whether it should already be considered in the preliminary design phase [25].

The flight dynamics of a flexible-model similar to SHAMPO has been considered, including the geometry of the aircraft, aerodynamic data and mass, flexural rigidity, and torsional rigidity distributions [31]. The wing of the aircraft consists of a right-half wing and left-half wing modelled as beams undergoing bending and torsion. The remaining members are assumed to be rigid. The equations of motion are obtained by means of the Lagrangian equations in quasi-coordinates. The resulting equations are nonlinear ordinary differential equations for the rigid body translations and rotations, and the boundaryvalue problems for the elastic deformations. The distributed variables are discretized in space using the Galerkin's method. Using a perturbation approach, the resulting set of non-linear ordinary differential equations are separated into a set of zero-order equations for the rigid body variables and a set of first-order equations for the perturbations in the rigid body variables and elastic deformations. The zero-order equations are used to design the desired manoeuvres. The first-order equations are used to assess the stability of the aircraft on the chosen flight paths and to design feedback controls to maintain stable flights.

In the numerical example, steady level flights at three different forward velocities have been considered $[31]$. The required control inputs that permit the flight and the resulting static deflections have been computed. The stability of the aircraft about these trims has been dealt with by inspecting the eigenvalues of the first-order (perturbation) equations. The aircraft has been found to be unstable in one of the trims and marginally stable in the other two. These results have been compared with the results of the quasi-rigid aircraft and the restrained aircraft models. Moreover, it has been shown that a control design based on the quasi-rigid aircraft model can destabilize the aircraft and that the full model must be used for a successful feedback control.

\section{CONCLUSION}

The results of this preliminary study show that it could be possible to obtain a very long endurance high altitude platform for Earth observation and telecommunication applications, at least for low latitude sites in Europe and for several months of continuous operation.

A BWB configuration of Solar HALE Aircraft has been obtained as a result of the preliminary design. The BWB solution seems to be the best compromise between performance available surface for solar- cells and volume for multi-payload purposes. The numerical aerodynamic results obtained show the availability of suitable airfoils for operation at low Reynolds numbers.

The structural concept layout has been defined and designed according to regulation requirements. The preliminary analytical and FE results showed a good correlation. The assumed structural concept, sandwich wing-box spar, demonstrates low structural mass and satisfactory classical flutter behaviour. According to airworthiness regulations a preliminary flight dynamic and flutter analysis has been carried out. Moreover, when the airplane shows highly flexible wings an advanced aeroelastic behaviour should be considered. Considering the case of a typical HALE UAV, a flutter speed reduction of up to 42 per cent with respect to classical analysis has been obtained considering a $2.5 \mathrm{~m}$ wing tip deflection.

\section{ACKNOWLEDGEMENTS}

The authors acknowledge the important contribution made by the following funding programmes.

1. HELIPLAT ${ }^{\circledR}$. 'Design of High Altitude Solar-powered Platform for Telecommunication and Earth Observation Applications'. ASI (Italian Space Agency). Contracts 1995-99. Coordinator: Prof. G. Romeo

2. HELINET: (Heliplat Network). 'Network of the Stratospheric Platforms for Traffic Monitoring, Environmental Surveillance and Broadband Services'. EC $5^{\circ} \mathrm{FP}$ - Contract IST-1999-11214, 2000-03; Coordinator: Polito. WP Leader of Heliplat ${ }^{\circledR}$ Design and Manufacturing: Prof. G. Romeo

3. CAPECON. 'Civil UAV Applications and Economic Effectivity of Potential Configuration Solutions'. EC $5^{\circ}$ FP - Contract GRD1-2001-40162, 2002-05. Coordinator: IAI. - WP Leader of 3 HALEs Design: Prof. G. Romeo.

4. STRATOS. 'Stratospheric platform - a definition study for an ESA system'. ESA Contract, 20022004. Coordinator: Airobotics -WP Leader Aerodynamic Platform Study: Prof. G. Romeo.

5. UAVNET. 'Civilian UAV Thematic Network: Technologies, Applications, Certification'. EC $5^{\circ} \mathrm{FP}$, G4RM-CT-2001-05. Coordinator: IAI

\section{REFERENCES}

1 Cohen, D. 2005 Global markets for civil and commercial UAVs. Frost \& Sullivan Interactive Briefing, UAVNET, available from http://www.uavnet.com.

2 Anon. Eternal airplane. The lift-off of unmanned solarelectric wings. Pop. Sci., 1994, 100, 70-75. 
3 Hall, D. W., Watson, D. A., Tuttle, R. P., and Hall, S. A. Mission analysis of solar powered aircraft. NASA CR172583, 1985.

4 Hall, D. W. and Hall, S. A. Structural sizing of a solar powered aircraft. NASA CR-172313, 1984.

5 Youngblood, J. W., Talay, T. A., and Pegg, R. J. Design of long endurance-endurance unmanned airplanes incorporating solar and fuel cell propulsion. AIAA paper 84-1430, 1984.

6 Romeo, G. Design proposal of high altitude very-long endurance solar powered platform for earth observation and telecommunication applications. 48th International Astronautical Congress, Turin, October 1997, paper no. IAF-97-M.2.05.

7 Romeo, G., Frulla, G., Cestino, E., and Corsino, G. HELIPLAT: design, aerodynamic, structural analysis of long-endurance solar-powered stratospheric platform. J. Aircr., 2004, 41(6), 1505-1520.

8 Romeo, G. and Frulla, G. HELIPLAT: high altitude verylong endurance solar powered UAV for telecommunication and earth observation applications. Aeronaut. J., 2004, 108(1084), 277-293.

9 Romeo, G. Manufacturing and testing of graphiteepoxy wing box and fuselage structures for a solar-powered UAV-HAVE. 21st ICAS Congress, Melbourne, September 1998, paper A98-31591.

10 Romeo, G. Design of high altitude very-long endurance solar powered platform for earth observation and telecommunication applications. Aerotecnica Missili E Spazio, 1998, 77(3-4), 88-99.

11 Romeo, G. and Frulla, G. HELIPLAT: aerodynamic and structural analysis of HAVE solar powered platform. 1st AIAA Technical Conference and Workshop on Unmanned aerospace vehicles, systems, technologies and operations, Portsmouth, USA, 20-23 May 2002.

12 Romeo, G., Frulla, G., and Fattore, L. HELIPLAT: high altitude very long endurance solar powered UAV for telecommunication application. FEM analysis, manufacturing and testing of $21 \mathrm{~m}$ long CFRP wing box. In Proceedings of the Applied Vehicle Technology Panel Symposium on Unmanned vehicle for aerial, ground and naval military operations, NATO, RTO, Ankara, Turkey, October 2000, paper no. 12.

13 Frulla, G. Aeroelastic behaviour of a solar-powered high-altitude long endurance unmanned air vehicle (HALE-UAV) slender wing. Proc. Instn Mech. Engrs, Part G: J. Aerospace Engineering, 2004, 218(G3), 179188.

14 Romeo, G., Frulla, G., Cestino, E., and Corsino, G. HALE-UAV solar configuration: aerodynamic and structure analysis, 2nd Iteration. CAPECON consortium report ID4.2.2/2e, January 2004.

15 Frulla, G. Preliminary reliability design of a solar powered high altitude very long endurance unmanned air vehicle. Proc. Instn Mech. Engrs, Part G: J. Aerospace Engineering, 2002, 216, 189-196.

16 Bojoi, R., Lazzari, M., Profumo, F., and Tenconi, A. Digital field-oriented control for dual three-phase induction motor driver. IEEE Trans. Ind. Appl., 2003, 39(3), 752-760.

17 Etkin, B. and Reid, L. Dynamics of flight: stability and control, 1996 (J. Wiley \& Sons, New York).
18 Perkins, C. and Hage, R. Airplane performance stability and control, 1949 (John Wiley \& Sons, New York).

19 Raymer, D. P. Aircraft design: a conceptual approach, 1999 (AIAA Education Series, New York).

20 Natham, J. K. A code for calculating the nonlinear aerodynamic characteristic of arbitrary configuration, VSAERO user's manual version 6.2, 2001 (Analytical Methods, Inc., Washington, USA).

21 Matlab-Simulink User's Manual, copyright 1984-1999 (The MathWorks, Inc., Natick, MA, USA).

22 Bisplinghoff, R. L., Ashley, H., and Halfman, R. L. Aeroelasticity, 1996, p. 880 (Dover Science, New York).

23 Dowell, E., Edwards, J., and Strganac, T. Nonlinear aeroelasticity. J. Aircr., 2003, 40(5), 857-874.

24 Romeo, G., Frulla, G., Cestino, E., Marzocca P., and Tuzcu I. Nonlinear aeroelastic modelling and experiments of flexible wings. 47th AIAA/ASME/ASCE/ AHS/ASC SDM Conference, Newport, Rhode Island, USA, 2006, p. 15.

25 Cestino, E. Design of very long-endurance solar powered UAV. PhD Thesis, Department of Aerospace Engineering, Politecnico di Torino, 2006.

26 Hodges, D. H. and Dowell, E. H. Non-linear equations of motion for the elastic bending and torsion of twisted non uniform rotor blades. NASA TN D-7818, 1974.

27 Crespo Da Silva, M. R. M. Non-linear flexural-flexuraltorsional-extensional dynamics of beams - I. Formulation. Int. J. Solids Struct., 1988, 24(12), 1225-1234.

28 Sedaghat, A., Cooper, J. E., and Wright, J. R. Prediction of non linear aeroelastic instabilities. ICAS Congress, Harrogate, UK, 2000.

29 Romeo, G., Frulla, G., Cestino, E., and Marzocca, P. Non-linear aeroelastic behavior of highly flexible HALE wings. In Proceedings of 25th ICAS Congress, Hamburg, Germany, 3-8 September 2006, p. 11.

30 Meirovitch, L. Fundamentals of vibrations, 2001 (McGraw Hill, New York).

31 Tuzcu, I., Marzocca, P., Cestino, E., Romeo, G., and Frulla, G. Stability, control, and simulation of highaltitude-long-endurance UAVs. 47th AIAA/ASME/ ASCE/AHS/ASC SDM Conference, Newport, Rhode Island, USA, 2006, p. 16.

\section{APPENDIX}

\section{Notation}

$A R_{\mathrm{ht}}, A R_{\mathrm{w}}$

$b_{\mathrm{ht}}, b_{\mathrm{w}}$

$c_{\text {mean }}$

$C_{\mathrm{D}}, C_{\mathrm{L}}$

$N$

$P_{\text {req }}$

$R e$

$S_{\mathrm{ht}}, S_{\mathrm{w}}$

$V$

$W_{\text {af }}, W_{\text {tot }}$

W horizontal tail and wing aspect ratio horizontal tail and wing span mean aerodynamic chord drag and lift coefficients limit load factor required power for the horizontal flight

Reynolds number based on the mean aerodynamic chord horizontal tail and wing area platform airspeed airframe and total platform weight wing deflection 
Z

$\alpha$

$\eta_{\text {prop }}$ altitude

angle of attack

propulsion efficiency
$\Lambda_{\mathrm{ht}}, \Lambda_{\mathrm{w}}$

$\lambda$

$\rho$ horizontal tail and wing sweep angle

taper ratio

air density 